\title{
Nanobody-Based Immunosensor Detection Enhanced by Photocatalytic-Electrochemical Redox Cycling
}

\author{
Stanislav Trashin, Francisco Morales-Yánez, Saranya Thiruvottriyur Shanmugam, Linda Paredis, \\ Erik N. Carrión, Idalia Sariego, Serge Muyldermans, Katja Polman, Sergiu M. Gorun, \\ and Karolien De Wael*
}

Cite This: Anal. Chem. 2021, 93, 13606-13614

Read Online

ACCESS | Lill Metrics \& More | 回 Article Recommendations | S1 Supporting Information

ABSTRACT: Detection of antigenic biomarkers present in trace amounts is of crucial importance for medical diagnosis. A parasitic disease, human toxocariasis, lacks an adequate diagnostic method despite its worldwide occurrence. The currently used serology tests may stay positive even years after a possibly unnoticed infection, whereas the direct detection of a re-infection or a still active infection remains a diagnostic challenge due to the low concentration of circulating parasitic antigens. We report a time-efficient sandwich immunosensor using small recombinant single-domain antibodies (nanobodies) derived from camelid heavy-chain antibodies specific

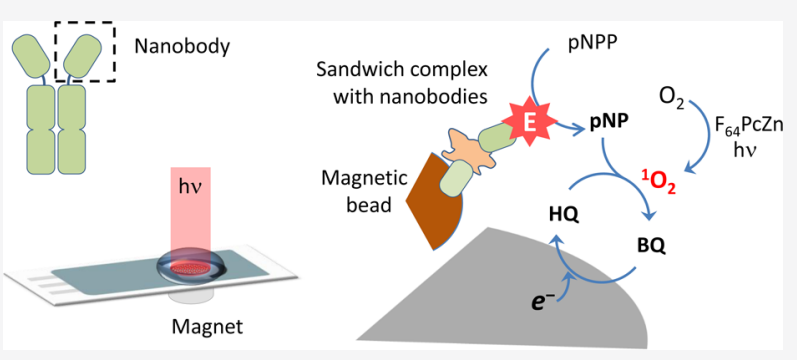
to Toxocara canis antigens. An enhanced sensitivity to $\mathrm{pg} / \mathrm{mL}$ levels is achieved by using a redox cycle consisting of a photocatalytic oxidation and electrochemical reduction steps. The photocatalytic oxidation is achieved by a photosensitizer generating singlet oxygen $\left({ }^{1} \mathrm{O}_{2}\right)$ that, in turn, readily reacts with $p$-nitrophenol enzymatically produced under alkaline conditions. The photooxidation produces benzoquinone that is electrochemically reduced to hydroquinone, generating an amperometric response. The light-driven process could be easily separated from the background, thus making amperometric detection more reliable. The proposed method for detection of the toxocariasis antigen marker shows superior performances compared to other detection schemes with the same nanobodies and outperforms by at least two orders of magnitude the assays based on regular antibodies, thus suggesting new opportunities for electrochemical immunoassays of challenging low levels of antigens.

I mmunoassays have become one of the most useful techniques in biomedical sciences with countless applications in diagnostics, pharmacokinetics, and bioequivalence studies due to the straightforward concept and substitution of radioactive labels by enzymes (leading to ELISA). ${ }^{1,2}$ The analytical performance of immunoassays largely relies on the affinity of antibodies that usually include either polyclonal antibodies (pAbs) obtained from animal immunization or hybridoma-derived monoclonal antibodies (mAbs). The latter have the advantage of comprising a homogeneous population of antibodies, resulting in more consistent and reproducible results. However, conventional antibodies are composed of heavy and light chains that severely impede their production in bacterial systems. Moreover, the lack of a systematic validation of commercial mAbs resulted in the lack of reproducibility in experiments performed with supposedly the same mAbs and well-known pAbs and mAbs obtained from different antibody resellers. ${ }^{3,4}$ These factors have led to the exploration of alternatives to mAbs with single-chain antibodies that can be successfully expressed in Escherichia coli in high yields and with minimum batch-to-batch variations.

The discovery of heavy chain-only antibodies in camelids paved the way for a more straightforward bioengineering, reproducible production of small single-domain antibodies, socalled nanobodies (Nbs). ${ }^{5}$ Unlike conventional pAbs and mAbs, Nbs are derived from the variable domain of heavychain antibodies (which are devoid of light chains) and consist of a single polypeptide of $\sim 15 \mathrm{kDa}$. Thus, $\mathrm{Nbs}$ retain full capacity to bind to cognate antigens with the same or even higher affinity compared to mAbs due to an extra-long fingerlike-shaped complementarity-determining region (CDR3). In addition, $\mathrm{Nbs}$ can be reproducibly obtained in high yields in prokaryotic and eukaryotic systems. Nbs can be also used as modular entities in protein engineering and expressed as multimeric fusions, or in combination with enzymes or sitespecific tags.

Many Nb-based analytical detection systems have been developed, focusing in particular on medical diagnostics. ${ }^{6}$ Conversely, $\mathrm{Nb}$-based electrochemical immunosensors remain

Received: July 8, 2021

Accepted: September 17, 2021

Published: September 29, 2021 
substantially less established and include the detection of procalcitonin, ${ }^{7}$ apolipoprotein- $\mathrm{A} 1,{ }^{8}$ cystatin $\mathrm{C},{ }^{9}$ aflatoxin $\mathrm{B}_{1},{ }^{10}$ pyrethroid insecticides, ${ }^{11}$ and the toxic microalgae Alexandrium minutum. ${ }^{12}$ The high sensitivity of electrochemical techniques combined with the high affinity of Nbs affords the detection of analytes at unprecedentedly low levels.

We have recently developed an electrochemical method based on Nbs, HRP label, and magnetic beads for diagnosis of the active form of human toxocariasis (HT), a parasitic disease caused by the accidental ingestion of Toxocara canis eggs. ${ }^{13,14}$ Although this is the most sensitive technique to date, the found concentrations of specific antigens in real samples are scattered close to the LOD, ${ }^{15}$ warranting further improvement of the method aimed at lowering the LOD.

The detection of active HT infections remains a diagnostic challenge due to the very low level of circulating parasitic antigens (T. canis excretory-secretory antigens, TES) present in the serum during the course of the disease. Furthermore, the only standardized diagnostic tool for HT is serology that detects specific anti-TES IgG by ELISA and Western blot. ${ }^{16}$ These approaches have the notorious disadvantage of remaining positive even years after infection due to the persisting seropositivity. Therefore, a positive test must be carefully interpreted together with clinical and epidemiological data. ${ }^{17}$ In this context, we note that alkaline phosphatase (ALP) is one of the most popular enzymatic labels in immunoassays that can be detected either optically or electrochemically (Figure 1A). Discovery of nanobodies opened new opportunities for bioengineering of advanced immunoreagents (Figure 1B), while development of electrochemical immunosensors addressed improvements in the reading step. In contrast to optical assays (i.e., ELISA), electrochemical immunosensors retain the ALP label at the electrode surface. This results in a high steady-state concentration of the enzymatic product at the electrode surface shortly after adding the reagents without the need of a reaction development step. To improve assay performances, the ALP enzymatic substrate and measuring buffer were optimized. $^{18-20}$ In particular, phosphorylated ascorbic acids ${ }^{19}$ and ferrocene derivatives ${ }^{18}$ were suggested as alternatives to phosphorylated phenols to avoid electrode fouling. Moreover, enzymatic recycling systems ${ }^{21,22}$ can additionally amplify the ALP assay. ${ }^{23-27}$ However, a mismatch in the optimal $\mathrm{pH}$ for ALP and the recycling enzymes as well as the generally poor reproducibility and stability of enzymes during and after sensor manufacturing processes limits the practical applicability of such schemes.

We report here the application of our recently introduced concept for detection of phenols using a chemically robust photocatalyst, a robust, fully fluorinated zinc phthalocyanine with bulky perfluoroalkyl peripheral groups. ${ }^{28}$ In contrast to enzymatic recycling systems, the photocatalyst is fully compatible with the ALP assay conditions. Moreover, the amperometric detection of $p$-nitrophenol $(\mathrm{pNP})$ is conducted at a comparatively low potential due to the photocatalytic oxidation-electrochemical reduction redox cycling (Figure 1C), which is driven by light and can be switched off on demand to additionally measure the baseline signal. This approach was adopted for the detection of TES to enhance the sensitivity and robustness of the electrochemical immunosensor based on ALP-labeled Nbs.

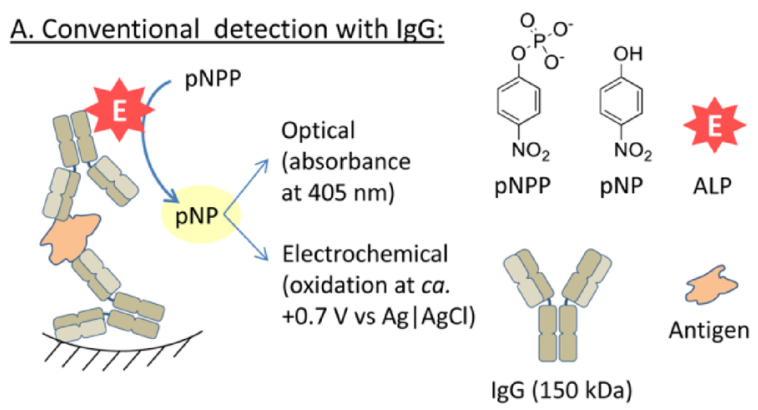

B. Advanced ELISA with $\mathrm{Nb}$ :

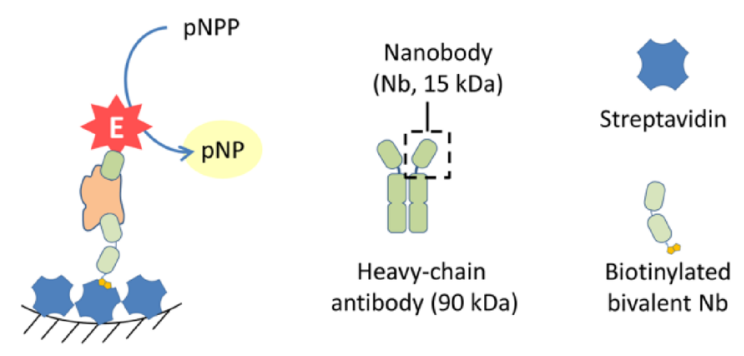

C. New photoamperometric detection with $\mathrm{Nb}$ :

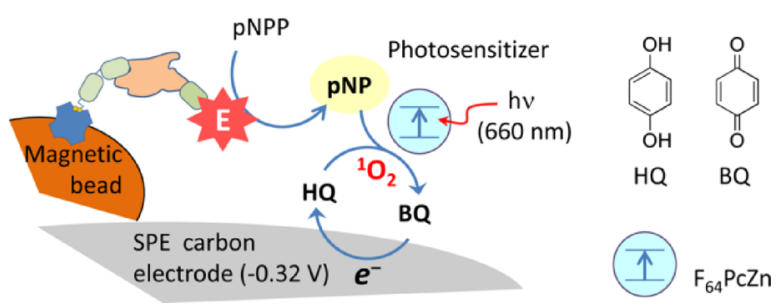

Figure 1. (A) Conventional detection scheme based on alkaline phosphatase (ALP)-labeled antibodies (IgG) with optical or electrochemical readouts. (B) Advanced ELISA based on previously reported Nbs with oriented immobilization. (C) New photoamperometric detection scheme based on the advanced $\mathrm{Nbs}$ and the photosensitized oxidation-electrochemical reduction redox cycling (shown in bold).

\section{EXPERIMENTAL SECTION}

Preparation of TES, Capture, and Detection Nanobodies. Production and purification of TES antigens were carried out as previously reported. ${ }^{29}$ The concentration of TES in the stock solution was determined from absorbance at 280 $\mathrm{nm}$ (OD280 of 1 corresponds to $1 \mathrm{mg} / \mathrm{mL}$ ) in line with our previous works. ${ }^{13-15}$ Library construction, selection, production, and purification of $\mathrm{Nbs}$ were done according to Conrath et al. ${ }^{30}$ and described in detail previously. ${ }^{13}$ Capture $\mathrm{Nb}(\mathrm{Nb}$ 2TCE49) was prepared as bivalent-monospecific construct in vivo biotinylated by co-expressing the pACYC184 plasmid (Avidity, USA) containing the pBirACm enzyme. Detection $\mathrm{Nb}$ (Nb 1TCE39), which recognizes a different, nonoverlapping epitope of TES compared to capture $\mathrm{Nb}$, was expressed from the pHEN6c vector containing only a His-Tag. After purification, detection $\mathrm{Nb}$ was chemically coupled with ALP using a commercial kit (ab102850, Abcam, UK).

Electrode Preparation. The supported photosensitizer ( 3 wt $\% \mathrm{~F}_{64} \mathrm{PcZn}$ on $\mathrm{TiO}_{2}$ Aeroxide P25) was prepared as described previously. ${ }^{28}$ A total of $3 \mu \mathrm{L}$ of $10 \mathrm{mg} / \mathrm{mL}$ suspension of the supported photosensitizer in MQ water was drop-casted on carbon screen printed electrodes (SPE, ItalSens IS-C, PalmSens). After drying, the modified electrodes were kept in the absence of light and humidity. 
Photoelectrochemical Detection of pNP. A pNP (>99\%, Fluka) stock solution of $50 \mathrm{mM}$ was prepared in absolute $\mathrm{EtOH}$ and added in $0.1 \mathrm{M}$ glycine $\mathrm{pH} 9.6$ buffer containing $1 \mathrm{mM} \mathrm{ZnCl}_{2}$ and $1 \mathrm{mM} \mathrm{MgCl}_{2}$. A drop of $90 \mu \mathrm{L}$ of pNP solution of variable concentration was placed on the modified SPE electrode, and the position of the working electrode was aligned with the laser used for illuminations, a red $660 \mathrm{~nm}$ diode laser (Roithner Lasertechnik, Austria) with an output power of $30 \mathrm{~mW}$ and spot diameter of $3 \mathrm{~mm}$.

The electrochemical measurements were conducted using a $\mu$ Autolab III (Metrohm Autolab, the Netherlands) instrument. The photocurrent was obtained by subtraction of the dark background current recorded just before illumination. The Ag pseudo-reference electrode has a potential of $c a .+0.12 \mathrm{~V} v \mathrm{~s}$ SCE in the used glycine buffer.

Determination of ALP Activity. The ALP activity was determined spectrophotometrically at $25{ }^{\circ} \mathrm{C}$ using an AvaSpec$2048 \mathrm{~L}$ spectrophotometer (Avantes, the Netherlands) in the $0.1 \mathrm{M}$ glycine $\mathrm{pH} 9.6$ buffer containing $1 \mathrm{mM} \mathrm{MgCl} 2$ and $\mathrm{ZnCl}_{2}$. For the measurements, ALP from calf intestine (ab102850, Abcam, UK) was injected in the measuring buffer containing $1 \mathrm{mM}$ pNPP (>98\%, MP Biomedicals, USA). Then, reaction progress was monitored at $410 \mathrm{~nm}\left(\varepsilon_{\mathrm{pNP}}=1.82 \times 10^{4}\right.$ $\mathrm{M}^{-1} \cdot \mathrm{cm}^{-1}$ ) for $5 \mathrm{~min}$. The slope of the initial linear segment was plotted as a function of ALP concentration (in the 10-500 $\mathrm{ng} / \mathrm{mL}$ range). The linear graph corresponds to a specific activity of $46.4 \pm 2.5 \mathrm{U} / \mathrm{mg}$ ( $\mu \mathrm{mol}$ pNP per min per mg ALP).

Photoamperometric Detection of ALP. The measurements of the ALP were conducted at room temperature (22 ${ }^{\circ} \mathrm{C}$ ) in the glycine buffer. ALP was injected in a drop of $1 \mathrm{mM}$ pNPP, which was previously placed on the modified electrode. The photocurrent was measured at continuous or periodic illumination. The slope of the time-dependent growth of the photocurrent was determined, similar to the optical assay procedure. The slope was plotted as a function of ALP concentration. Using the known sensitivity of the electrodes to pNP, the obtained slopes can be converted into the specific activity of ALP, which, in this way, is obtained independent of the spectrophotometric method.

Photoamperometric TES Detection. The detection format used in the present work (Figure 1B) was adopted from our previous work on electrochemical detection of TES using Streptavidin precoated magnetic beads and the same Nbs. ${ }^{13-15}$ However, in the present work, Nb-ALP was used instead of $\mathrm{Nb}-\mathrm{HRP}$ as detection $\mathrm{Nb}$. In brief, Streptavidin precoated magnetic beads (Dynabeads M-280, ThermoFisher Scientific) were incubated with capture Nb 2TCE49 $(2 \mu \mathrm{g}$ per $1 \mathrm{mg}$ beads) in PBS containing 0.05\% Tween 20 (PBST20 buffer) for $1 \mathrm{~h}$ on a rotary shaker. Next, the beads were washed $5 \times$ with PBST20 and re-suspended in PBST20 to obtain a 5 $\mathrm{mg} / \mathrm{mL}$ suspension. Detection Nbs were diluted in PBS to get $500 \mathrm{ng} / \mathrm{mL}$. Then, $10 \mu \mathrm{L}$ of the modified beads and $10 \mu \mathrm{L}$ of diluted detection Nbs were added in each microtube containing $0.5 \mathrm{~mL}$ of TES solution, vortexed, and placed on a rotary shaker for $30 \mathrm{~min}$. Next, the beads were washed $2 \times$ with PBST20 and, if not used immediately, left in PBS without vortexing. Approximately $5 \mathrm{~min}$ before the measurements, PBS was replaced with the measuring buffer $(0.1 \mathrm{M}$ glycine $\mathrm{pH} 9.6$ containing $1 \mathrm{mM} \mathrm{ZnCl}$ and $1 \mathrm{mM} \mathrm{MgCl}_{2}$ ) to ensure activation of ALP by $\mathrm{Mg}^{2+}$ and $\mathrm{Zn}^{2+}$ cations. Just before measurements, the beads were concentrated and transferred in a small amount of measuring buffer $(7-10 \mu \mathrm{L})$ on the working electrode covered with a $90 \mu \mathrm{L}$ drop of measuring buffer containing $0.5 \mathrm{mM}$ pNPP. Photoamperometric measurements were conducted at a fixed potential of $-0.32 \mathrm{~V}$ using the red light diode laser aligned with the position of the working electrode. For comparison, conventional square wave voltammetry (SWV; amplitude, $0.05 \mathrm{~V}$; frequency, $20 \mathrm{~Hz}$ ) was used to detect ALP on unmodified SPEs without illumination. All measurements were conducted at room temperature and at least in triplicate.

Detection of TES in Serum. Commercially available serum from human male $\mathrm{AB}$ plasma (Sigma-Aldrich) was diluted 1/10 with PBS and spiked with TES. Pooled serum of nine highly positive samples (OD in anti-TES-IgG assay $>1.7$, from a previous study on the seroprevalence of $T$. canis in children from Cuba. ${ }^{31}$ Informed consent of the parents or legal guardians of the children was obtained.) containing endogenous immunoglobulins with specificity to TES was used as a control. The serum was diluted $1 / 10$ with PBS and spiked with TES or subjected to the immune-complex dissociation (ICD) procedure, similar to the protocol developed by RodriguezCaballero et al. ${ }^{32}$ Briefly, the diluted serum was mixed with the same volume of $100 \%$ glycerol and double volume of $0.5 \mathrm{M}$ EDTA ( $\mathrm{pH} \mathrm{7.4).} \mathrm{Then,} \mathrm{the} \mathrm{mixture} \mathrm{was} \mathrm{boiled} \mathrm{for} 6 \mathrm{~min}$ and centrifuged at $19,000 \mathrm{~g}$ for $10 \mathrm{~min}$. The supernatant was separated and spiked with TES for photoamperometric detection.

Sandwich ELISA. Sandwich ELISA was performed according to our previously reported optimized protocol, ${ }^{13,14}$ but, here, with $\mathrm{Nb}$ coupled to ALP. The Nb-ALP conjugate was used in different concentrations, viz., 20, 50, or $100 \mathrm{ng} /$ $\mathrm{mL}$, with only a minor effect on the result. The conjugate was incubated for $1 \mathrm{~h}$ at room temperature with shaking.

In the last step, the wells were washed and the fresh substrate buffer $(0.1 \mathrm{M}$ glycine $\mathrm{pH} 9.6$ containing $1 \mathrm{mM}$

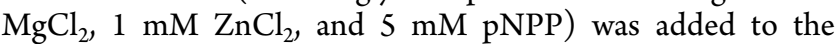
wells. The reaction developed at $37{ }^{\circ} \mathrm{C}$ in the dark with shaking. Readings of absorbance at $450 \mathrm{~nm}\left(\varepsilon_{\mathrm{pNP}}=3.8 \times 10^{3}\right.$ $\left.\mathrm{M}^{-1} \cdot \mathrm{cm}^{-1}\right)$ were taken after $15,30,60$, and $90 \mathrm{~min}$. All measurements were done in triplicate, except for blanks, which were measured in six separate readings. The limit of detection (LOD) was calculated as $3 \times$ the standard deviations of blanks divided by the sensitivity in the low concentration range.

\section{RESULTS AND DISCUSSION}

pNP Photoelectrochemical Detection. The amperometric detection of pNP was implemented by employing photosensitized oxidations triggered by the highly active photosensitizer, fully fluorinated phthalocyanine $\mathrm{F}_{64} \mathrm{PcZn}$, which is capable to form singlet oxygen $\left({ }^{1} \mathrm{O}_{2}\right)$ under red light illumination. ${ }^{28,33}$ The photosensitized oxidation of $\mathrm{pNP}$ yields an oxidized product, benzoquinone (BQ), ${ }^{34}$ which is electroactive and can be electrochemically transformed into a reduced product, hydroquinone (HQ), giving a cathodic current useful in electroanalysis. ${ }^{28}$ Since HQ can also undergo the photosensitized oxidation producing $\mathrm{BQ}$, the process forms a redox cycle (Figure 1C, part of the scheme in bold), thus enhancing the steady-state amperometric responses. The cathodic current from the electrochemical reduction of $\mathrm{BQ}$ into $\mathrm{HQ}$ is higher when the photooxidation takes place in the vicinity of the electrode surface, which increases the local nearelectrode concentration of $\mathrm{BQ}$.

To demonstrate the possibility of photoamperometric detection of pNP under conditions suitable for analysis with ALP-labeled immunoreagents, we used glycine buffer $\mathrm{pH}$ 9.6, 
which is the same buffer used in the ELISA based on the same immunoreagents. The applied potential is an important parameter of the suggested amperometric detection scheme and affects both the sensitivity to phenols and background currents in blank buffers. ${ }^{35}$ Figure 2 illustrates the effect of

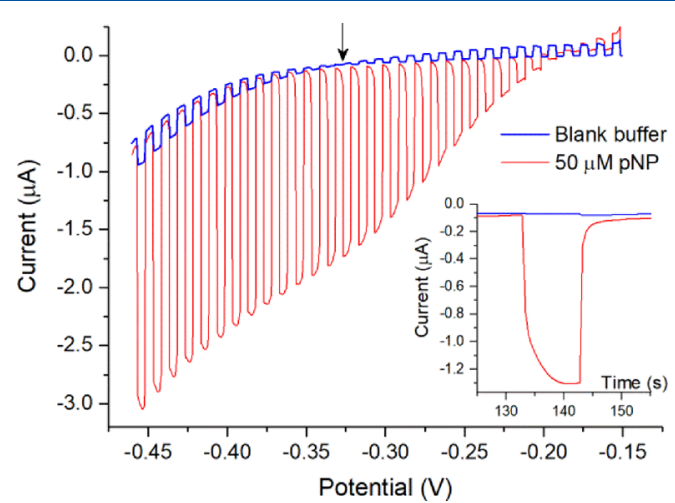

Figure 2. Light-chopped linear sweep voltammetry of the modified SPE electrode in glycine buffer $\mathrm{pH} 9.6$ in the absence and presence of $50 \mu \mathrm{M}$ pNP. Scan rate, $1 \mathrm{mV} / \mathrm{s}$. The inset depicts the chronoamperometric behavior at a fixed potential of $-0.32 \mathrm{~V}$.

applied potential on photoamperometric detection of $50 \mu \mathrm{M}$ pNP in comparison to the blank buffer. pNP shows a typical wave-like profile with a half-wave potential at $-0.27 \mathrm{~V}$ and saturation at around $-0.40 \mathrm{~V}$ (see also Figure S1 for blanksubtracted data). However, photocurrents in the blank buffer also become noticeable at $-0.40 \mathrm{~V}$, which required the use of $-0.32 \mathrm{~V}$, where sensitivity reaches $80 \%$ of the value at -0.45 $\mathrm{V}$, but the blank photocurrent is negligible (Figure 2, inset).

Interestingly, minor anodic photocurrents were observed in the blank buffer at potentials more positive than $-0.32 \mathrm{~V}$, most likely due to the oxidation of superoxide ions formed via photoinduced electron-transfer reactions involving $\mathrm{O}_{2}$ and side reactions of ${ }^{1} \mathrm{O}_{2}$ with components of the buffer and the modified electrode. A comparatively low formal potential of $E^{\circ \prime}\left(\mathrm{O}_{2} / \mathrm{O}_{2}^{-}\right)=-0.265 \mathrm{~V}$ vs $\operatorname{SCE}^{36}$ (ca. $-0.38 \mathrm{~V}$ vs the pseudo-reference Ag electrode used), as determined by cyclic voltammetry in $0.1 \mathrm{M} \mathrm{NaOH}$, corresponds well to the region where the anodic photocurrent appears. The cathodic photocurrents in the blank buffer at potentials more negative than $-0.32 \mathrm{~V}$ were attributed to the reduction of $\mathrm{O}_{2}^{-}, \mathrm{H}_{2} \mathrm{O}_{2}$, and likely ${ }^{1} \mathrm{O}_{2}$ generated in the proximity of the electrode $\left({ }^{1} \mathrm{O}_{2}\right.$ has a limited average diffusion length due to its short lifetime. Less than $0.1 \%$ of produced ${ }^{1} \mathrm{O}_{2}$ will diffuse $250 \mathrm{~nm}$ in water even in the absence of any quenchers). ${ }^{37,38}$ Nevertheless, the blank photocurrents are rather minor and can be minimized by the careful selection of the working potential. Eventually, the potential of $-0.32 \pm 0.01 \mathrm{~V}$ provided the lowest blank and was used in subsequent work.

Effects of Variable pNP Concentration. Figure 3A shows the chronoamperograms recorded at $-0.32 \mathrm{~V}$ in solutions containing $0.01-1.0 \mathrm{mM}$ pNP. After switching the light on, a cathodic photocurrent appears and reaches steadystate values within $15 \mathrm{~s}$ ( $5 \mathrm{~s}$ in the low concentration range). The pNP photocurrent is linearly proportional to the pNP concentration till $100 \mu \mathrm{M}$ while leveling off at higher values. In contrast to the steady-state current, the peak current (which is observed for high concentrations shortly after the light is on) keeps growing with the concentration till 500-750 $\mu \mathrm{M}$, expanding the practically useful concentration range (Figure $3 \mathrm{~B})$. The leveling off at around $500 \mu \mathrm{M}$ results from the limited solubility of oxygen (up to $260 \mu \mathrm{M}$ ) in air-saturated water. The sensitivity in the low concentration range was $-0.032 \mathrm{~A} / \mathrm{M}\left(-0.45 \mathrm{~A} / \mathrm{M} / \mathrm{cm}^{2}\right)$ with an LOD around $0.5 \mu \mathrm{M}$ $\mathrm{pNP}(3 \times \mathrm{SD})$.

To estimate the enhancement of the sensitivity due to the redox cycling mechanism, regular chronoamperometric curves were obtained for oxidation of $\mathrm{pNP}$ using a sufficiently large potential, $+0.85 \mathrm{~V} v s$ the used pseudo Ag reference SPE $(+0.97$ $\mathrm{V}$ vs SCE), which is $0.15 \mathrm{~V}$ more positive than the pNP oxidation peak potential obtained by SWV using the same conditions. A near steady-state current was observed by the $180 \mathrm{~s}$ time point. At this reading time, the sensitivity was only $0.09 \mathrm{~A} / \mathrm{M} / \mathrm{cm}^{2}$ with the LOD around $5 \mu \mathrm{M}(3 \times \mathrm{SD})$. Measuring a non-steady-state current at an earlier time, when the current decays steeply, increases the sensitivity (e.g., the sensitivity is twice higher at a reading time of $10 \mathrm{~s}$ ) but does not improve the actual LOD due to the increased variation in blanks. Thus, the redox cycling enhances the steady-state currents about fivefold compared to the regular amperometric detection while further improving detectability due to intrinsic baseline correction when switching the light on and off. The latter effect resembles the advantage of voltammetry techniques given that baseline correction allows the separation of a net peak current from a baseline current.

Detection of ALP Activity Correlated with Optical Assays. ALP dephosphorylates the phenolic group in pNPP
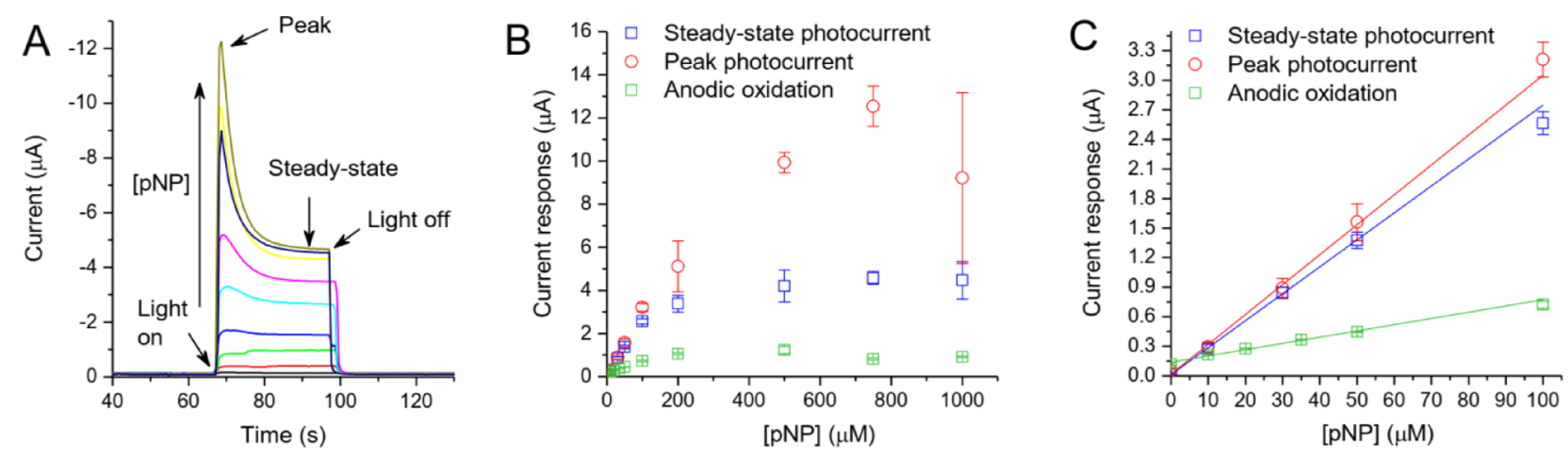

Figure 3. (A) Photoamperometric detection of $\mathrm{pNP}$ in glycine buffer $\mathrm{pH} 9.6$ at $-0.3 \mathrm{~V}$ using a red $659 \mathrm{~nm}$ laser pointer. (B) Calibration curves constructed for the peak current and steady-state currents (both cathodic) in photoamperometric detection and the near steady-state current (anodic) obtained in chronoamperometric detection at $+0.85 \mathrm{~V}$. (C) Zoomed-in linear region. Error bars represent SD $(n=3)$. 

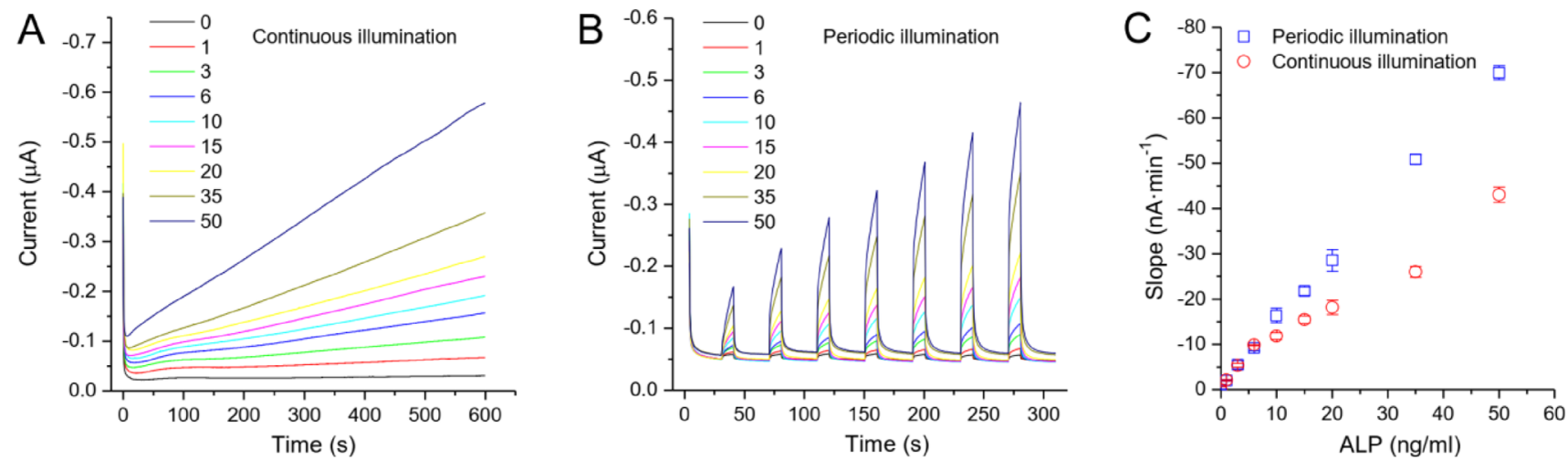

Figure 4. Photoamperometric detection of ALP activity in solution under (A) continuous and (B) periodic illumination. (C) Dependence of the slope on the amount of ALP. Background, $0.1 \mathrm{M}$ glycine buffer $\mathrm{pH} 9.6$ containing $1 \mathrm{mM} \mathrm{MgCl}$ and $1 \mathrm{mM} \mathrm{ZnCl}$. The numbers in the captions of panels (A) and (B) are the amount of ALP in $\mathrm{ng} / \mathrm{mL}$.
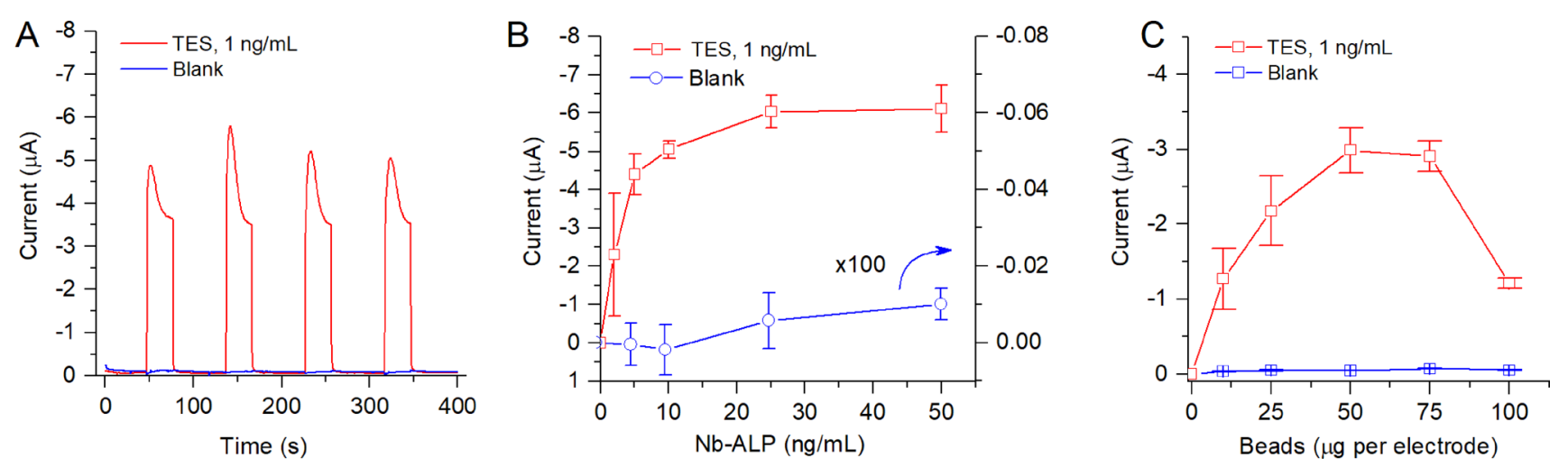

Figure 5. Effects of (A) measuring time, (B) concentration of the Nb-ALP conjugate, and (C) amount of beads on the detection of $1 \mathrm{ng} / \mathrm{mL}$ TES antigens in comparison to blanks.

releasing $\mathrm{pNP}$, which is of high practical interest in ELISA based on ALP-labeled immunoreagents. Moreover, pNPP is electrochemically inactive and thus can be used in electrochemical assays based on the same principle. We additionally discovered that $\mathrm{pNPP}$, in contrast to $\mathrm{pNP}$, does not result in any photocurrent. Thus, the ALP activity can be quantified photoelectrochemically with the setup described here.

Figure $4 \mathrm{~A}$ shows the behavior of the current upon the addition of different ALP concentrations under continuous illumination. The current rises in time with a slope proportional to the concentration of ALP, similar to conventional optical assays. To further improve the detectability of pNP and ALP, light-chopped amperometry was conducted (i.e., with periodic illumination instead of continuous illumination, Figure 4B). This causes the dependence of the ALP concentration slope to be linear over a wider ALP concentration range (Figure $4 \mathrm{C}$ ) with a value of $-1.60 \mathrm{nA}$ / $\mathrm{min} /\left(\mathrm{ng}_{\mathrm{ALP}} / \mathrm{mL}\right)$. Taking into account the sensitivity of the electrode to pNP $(-0.032 \mathrm{~A} / \mathrm{M})$ as obtained above, the slope gives a specific activity of $50 \pm 2 \mu \mathrm{mol} / \mathrm{min} / \mathrm{mg}_{\text {ALP }}(\mu \mathrm{mol} \mathrm{pNP}$ formed per min per $\mathrm{mg}$ of ALP). Measurements by the conventional optical assay at $25{ }^{\circ} \mathrm{C}$ in the same buffer resulted in a specific activity of $46.4 \pm 2.5 \mu \mathrm{mol} / \mathrm{min} / \mathrm{mg}_{\mathrm{ALP}}$ that matched well the activity obtained by the electrochemical assay. Under these conditions, the LOD for ALP determination by the photoamperometric method and the conventional optical method was almost the same and estimated as $0.2 \mathrm{ng} / \mathrm{mL}$ or $0.01 \mathrm{U} / \mathrm{L}$ ALP.
It is well-known that small amounts of $\mathrm{Mg}^{2+}$ and $\mathrm{Zn}^{2+}$ are necessary for the catalysis of ALP $\left(\mathrm{Mg}^{2+}\right.$ stabilizes the enzyme structure and $\mathrm{Zn}^{2+}$ participates in catalysis). Thus, $1 \mathrm{mM}$ $\mathrm{MgCl}_{2}$ and $1 \mathrm{mM} \mathrm{ZnCl}$ were present in the glycine substrate buffer as recommended by the generic ELISA protocol. In the absence of $\mathrm{Mg}^{2+}$ and $\mathrm{Zn}^{2+}$ or in the presence of only $\mathrm{Mg}^{2+}$, about $25 \%$ residual activity was measured photoelectrochemically and $10 \%$ was measured optically. This comparatively large drop in activity is explained by the preparation of the initial solutions in PBS buffer, which binds divalent cations. The presence of $\mathrm{Mg}^{2+}$ and $\mathrm{Zn}^{2+}$ in glycine-measuring buffer aims to recover and promote the activity. Noteworthily, some ELISA protocols require only $\mathrm{Mg}^{2+}$ in the measuring buffer, which is due to replacement of the PBS dilution buffer by the Tris dilution buffer to avoid washing of tightly bound $\mathrm{Zn}^{2+}$.

Detection of TES Antigens. As anticipated, the sensitivity of the detection step was high, starting with the first illumination at $50 \mathrm{~s}$ (Figure 5A). The photocurrent responses were usually maximal at the second illumination at $130 \mathrm{~s}$. However, at least three consecutive illuminations were conducted in all cases to ensure reproducibility of the data. The concentration of the Nb-ALP conjugate was varied from 2 to $50 \mathrm{ng} / \mathrm{mL}$ (Figure $5 \mathrm{~B}$ ). The responses increased steeply from 2 to $10 \mathrm{ng} / \mathrm{mL}$ and leveled off at $25 \mathrm{ng} / \mathrm{mL}$. However, a slight increase in the background was observed at 25 and 50 $\mathrm{ng} / \mathrm{mL}$, likely due to unspecific adsorption of the $\mathrm{Nb}$-ALP conjugate on the beads. Thus, $10 \mathrm{ng} / \mathrm{mL}$ was taken as the optimal concentration for the calibration curve. 

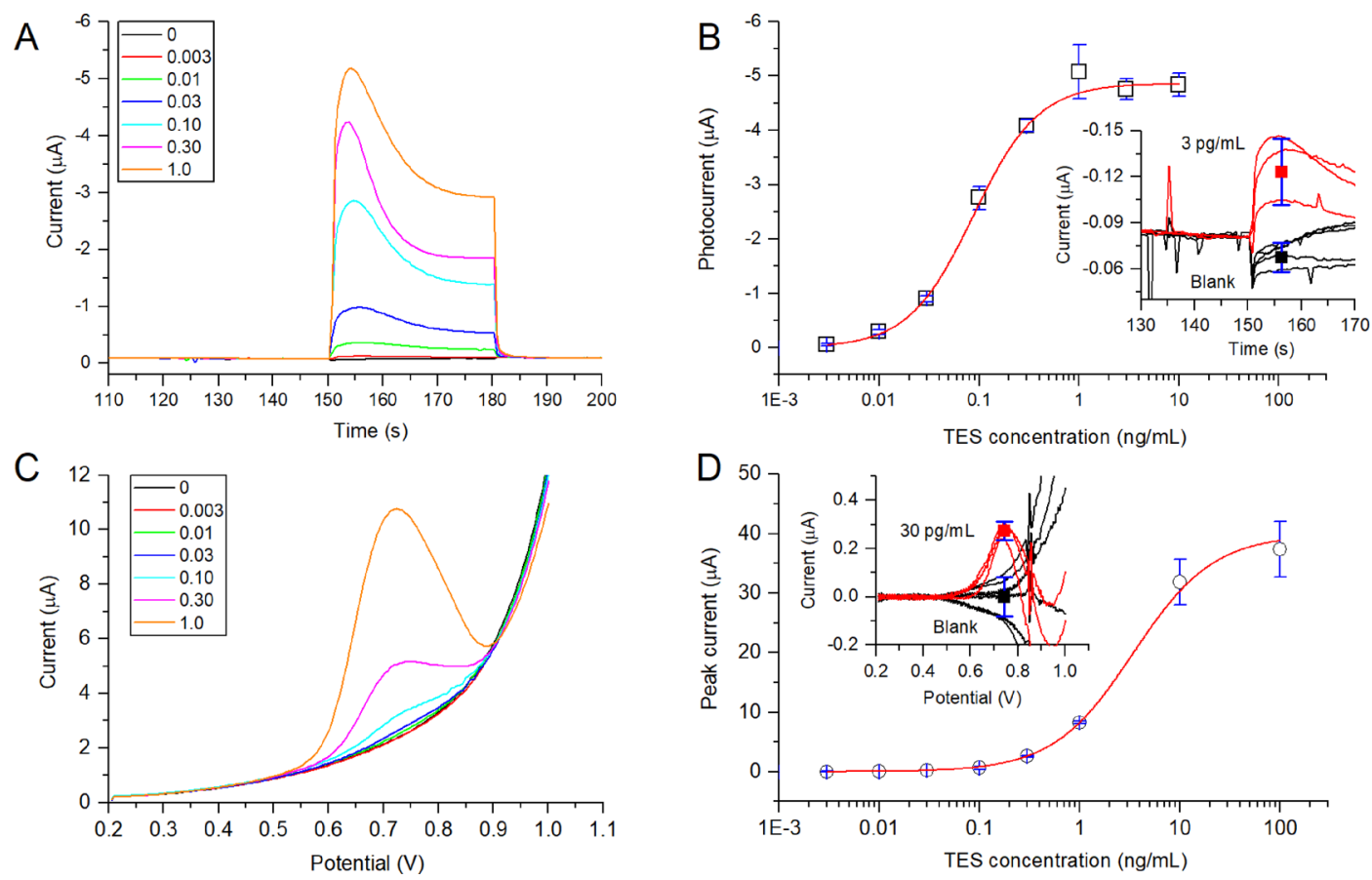

Figure 6. Calibration curves for detection of TES antigens obtained by (A, B) photoamperometric and (C, D) conventional SWV methods. Numbers in the legends (A, C) denote TES concentration. The insets (B, D) show the actual experimental curves for TES concentration near the LODs. The curves in the inset (B) are aligned to the same dark current before the illumination. The SWV curves in the inset (D) are given after subtraction of an average blank followed by a linear baseline correction (using linear fits between 0.2 and $0.5 \mathrm{~V}$ ).

Finally, the amount of magnetic beads used in a single measurement was varied (Figure 5C). An amount of $50 \mu \mathrm{g}$ was optimal in the used setup, which corresponds to our previous work with HRP-labeled Nbs. ${ }^{14}$ This amount of beads is visually just enough to cover the complete working electrode, thus involving most of the available sensor surface in the detection. A thicker layer of beads, which are dark brown, may dim the light for the underlying layer of the photosensitizer. The increase from 50 to $100 \mu \mathrm{g}$ of beads per electrode indeed hampers the response, decreasing it twofold. An estimation based on the bead diameter $(2.8 \mu \mathrm{m})$, bead density $(1.6 \mathrm{~g} /$ $\left.\mathrm{cm}^{3}\right)$, and geometric electrode area $\left(0.071 \mathrm{~cm}^{2}\right)$, as provided by the producers, suggests that $50 \mu \mathrm{g}$ of beads per electrode corresponds to the coverage of $0.7 \mathrm{mg} / \mathrm{cm}^{2}$ or $7 \mu \mathrm{m}(2-3$ monolayers) at random close packing. Nevertheless, the distribution of beads over the surface is not fully uniform. The layer is slightly thicker just above the center of the magnet, i.e., in the middle of the electrode. The use of $50 \mu \mathrm{g}$ gives a good compromise between the amount of Nb-ALP on the beads, leading to higher sensitivity, and dimming the light that reaches the photosensitizer, leading to lower sensitivity. In general, the optimal amount of beads is proportional to the electrode area and, thus, can be predicted for electrodes of other diameters by normalization per their electrode area.

Calibration Curves for TES Antigens. Figure 6A,B illustrates the photoamperometric detection of TES in a wide concentration range in comparison with the regular SWV technique (Figure 6C,D) and ELISA with the same reagents (Figure 7). In all cases, TES was well-detectable at $\mathrm{pg} / \mathrm{mL}$ levels, which is important for applications since the diagnostically relevant TES concentration is expected to be below $1 \mathrm{ng} / \mathrm{mL}$ and, taking into account the necessity of sample preparation, may rather be in the low $\mathrm{pg} / \mathrm{mL}$ level. ${ }^{13,14}$ In this view, photoamperometric detection is advantageous

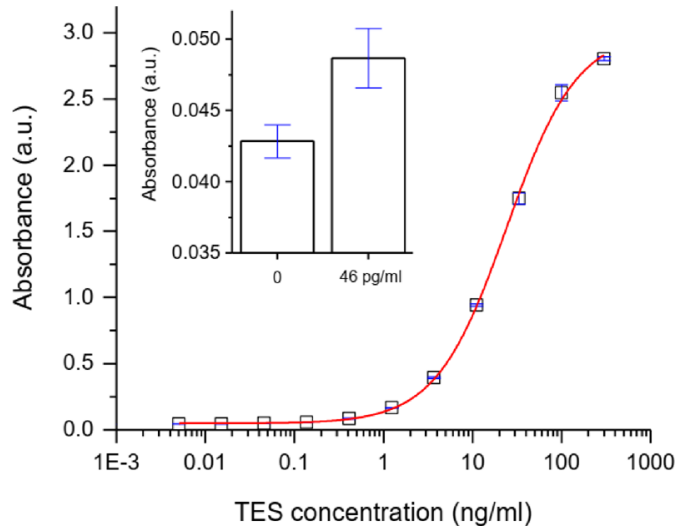

Figure 7. Detection of TES antigens by ELISA with the same immunoreagents used in the electrochemical methods. The inset shows the actual response for a TES concentration closest to the LOD in comparison to the blank.

with an LOD of $1 \mathrm{pg} / \mathrm{mL}$ (Table 1$)$ followed by SWV (LOD = $24 \mathrm{pg} / \mathrm{mL}$ ) and ELISA (LOD $=35 \mathrm{pg} / \mathrm{mL}$ ).

The other calibration curve parameters also drastically differ for the three methods (Table 1 ). The usable concentration range was the largest for ELISA $(0.05-100 \mathrm{ng} / \mathrm{mL})$ with an $\mathrm{EC}_{50}$ (half-maximal effective concentration) of $20 \mathrm{ng} / \mathrm{mL}$, which is $7 \times$ and $200 \times$ higher compared to $\mathrm{SWV}\left(\mathrm{EC}_{50}=3 \mathrm{ng} /\right.$ $\mathrm{mL})$ and photoamperometry $\left(\mathrm{EC}_{50}=0.1 \mathrm{ng} / \mathrm{mL}\right)$, respectively. This difference, however, should not be attributed to a change in the affinity of the immunoreagents but to a limitation by the sensors' maximal measurable concentration of pNP (Figure 3).

It is also interesting to compare sensitivities among the assays with the same $\mathrm{Nbs}$, expressed as slopes of linear correlations in the low concentration range (Table 1). The 
Table 1. Comparison of Methods for TES Antigen Detection

\begin{tabular}{|c|c|c|c|c|c|c|}
\hline method & immunoreagent & $\begin{array}{c}\text { slope (in the low concentration } \\
\text { range) }\end{array}$ & $\begin{array}{l}\text { usable concentration range } \\
(\mathrm{ng} / \mathrm{mL})\end{array}$ & $\begin{array}{l}\text { apparent } \mathrm{EC}_{50} \\
(\mathrm{ng} / \mathrm{mL})\end{array}$ & $\begin{array}{c}\text { LOD } \\
(\mathrm{ng} / \mathrm{mL})\end{array}$ & reference \\
\hline photoamperometric & $\mathrm{Nb}-\mathrm{ALP}$ & $31 \mu \mathrm{A} /(\mathrm{ng} / \mathrm{mL})$ & $0.003-1$ & 0.1 & 0.001 & $t w^{d}$ \\
\hline voltammetric (SWV) & $\mathrm{Nb}-\mathrm{ALP}$ & $8.6 \mu \mathrm{A} /(\mathrm{ng} / \mathrm{mL})$ & $0.03-10$ & 3 & 0.024 & tw \\
\hline amperometric & $\mathrm{Nb}$-HRP & $5.8 \mu \mathrm{A} /(\mathrm{ng} / \mathrm{mL})$ & $0.01-10$ & 1.5 & 0.006 & 14 \\
\hline ELISA & $\mathrm{Nb}-\mathrm{ALP}$ & 0.10 a.u. $/(\mathrm{ng} / \mathrm{mL})$ & $0.05-100$ & 20 & 0.035 & tw \\
\hline ELISA & $\mathrm{Nb}$-HRP & 0.11 a.u. $/(\mathrm{ng} / \mathrm{mL})$ & $0.3-200$ & 20 & 0.090 & 14 \\
\hline ELISA & $\begin{array}{l}\mathrm{mAb} / \mathrm{pAb} / \mathrm{IgG}- \\
\mathrm{HRP}\end{array}$ & & $0.1-1000$ & 10 & 0.440 & 32,40 \\
\hline ELISA & $\begin{array}{l}\mathrm{mAb} / \mathrm{pAb} / \mathrm{IgG}- \\
\mathrm{HRP}\end{array}$ & & $4-1000$ & 60 & $4^{a}$ & 41 \\
\hline ELISA & $\begin{array}{l}\mathrm{mAb} / \mathrm{pAb} / \\
\mathrm{IgG}-\mathrm{HRP}\end{array}$ & & $5-100$ & & $5^{b}$ & 39 \\
\hline ELISA & pAb-HRP & & $78-40,000$ & & $78^{c}$ & 42 \\
\hline ELISA & $\mathrm{mAb}-\mathrm{HRP}$ & & $20-25,000$ & & $20^{c}$ & 43,44 \\
\hline
\end{tabular}

slope was $5 \times$ higher for the photoamperometric sensor with $\mathrm{Nb}$-ALP compared to the amperometric sensor with $\mathrm{Nb}$ HRP. ${ }^{14}$ Yet, the slopes for the ELISAs with $\mathrm{Nb}$-ALP and NbHRP were the same (around 0.10 a.u./ $(\mathrm{ng} / \mathrm{mL})$ ) while also having an identical maximal absorbance of $c a .3$ a.u. at the highest concentration. This suggests that the performance of $\mathrm{Nb}$-ALP and Nb-HRP is about the same, whereas the enhancement in the sensitivity for the photoamperometric sensor results from the advanced detection scheme. Noteworthily, the LOD was $2 \times$ better for ELISA with Nb-ALP compared to the ELISA with Nb-HRP due to the only better reproducibility in blanks in the case of $\mathrm{Nb}$-ALP.

SWV allows subtracting a background current to obtain the specific peak current similar to photoamperometry. This is typically done by extrapolating a baseline to the peak position, which is, however, problematic for $\mathrm{pNP}$ due to a steep nonlinear background at the peak base. In this work, the shape was partially corrected by subtraction of an average blank curve followed by linear extrapolation of the baseline to obtain the data as in the Figure 6D inset, from which the current at the peak position can be read. This allows objective readings of responses and automatization in data processing, but the eventual LOD is rather high ( $20 \times$ higher compared to photoamperometry, whereas the slope is only $3.6 \times$ lower). If the background correction in SWV could be further improved, for example, by taking an alternative ALP substrate that is oxidized at a lower potential (e.g., $p$-aminophenylphosphate), the performance of the voltammetric sensor would be noticeably improved as well.

It is also possible to compare the slopes of the optical ELISA and the electrochemical sensors by converting the slopes to the same units. First, the a.u. of absorbance can be converted into pNP concentration using the extinction coefficient $\left(3.8 \times 10^{3}\right.$ $\left.\mathrm{M}^{-1} \cdot \mathrm{cm}^{-1}\right)$ and the optical path $(0.3 \mathrm{~cm}$ for $100 \mu \mathrm{L}$ solution in a well of the used ELISA plate). The concentration can be turned into the photocurrent using the sensitivity of the photoamperometric method to $\mathrm{pNP}(-0.032 \mathrm{~A} / \mathrm{M}$ as measured earlier in this work). The sensitivity of the ELISA thus corresponds to an equivalent of $3 \mu \mathrm{A} /(\mathrm{ng} / \mathrm{mL})$, which is $10 \times$ lower than the sensitivity of the photoamperometric sensor to TES. Obviously, a longer development time can give a proportionally higher sensitivity in the ELISA at low concentrations with, however, unavoidable saturation of the reading values at high concentrations. In other words, a development time of $15 \mathrm{~h}$ ( $10 \times$ standard time) would give a sensitivity comparable to that in the photoamperometric method. In contrast, the high sensitivity of the photoamperometric sensor is reached instantly due to the production of $\mathrm{pNP}$ right on the sensor surface, leading to a high local concentration of pNP. This effect is enhanced by the redox cycling process and improved baseline correction due to the modulation of the photoreactivity by light.

Detectability of TES in Serum. The need of lowering the detectability of TES antigens is met by its detection in spiked blank serum (10X diluted) and serum highly positive for antiTES-IgG $(10 \times$ diluted $)$ in comparison to PBS, all under the same experimental conditions (Figure 8). Not surprisingly,

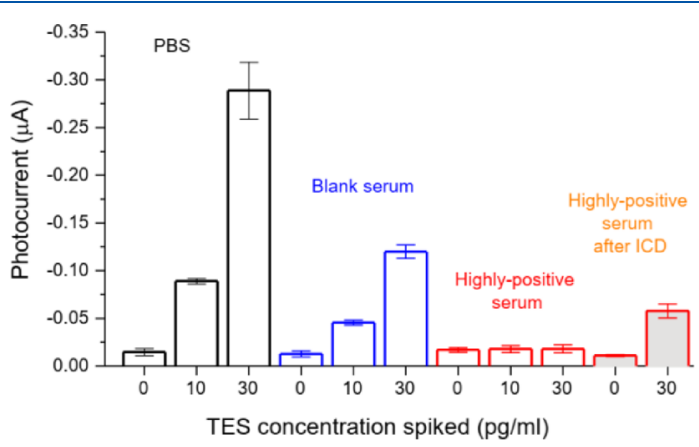

Figure 8. Detection of TES spiked in PBS, blank serum, and serum highly positive for anti-TES-IgG before and after the immunecomplex dissociation (ICD) treatment. In each case, the serum was diluted $1 / 10$ with PBS.

serum affected the detectability of TES, suppressing the sensitivity twofold compared to PBS. More importantly, serum containing large amounts of endogenous antibodies against TES completely suppressed the responses at 10 and $30 \mathrm{pg} / \mathrm{mL}$ TES levels. This means that endogenous antibodies block the epitopes recognized by at least one of the two Nbs used (the capture and detection $\mathrm{Nbs}$ recognize different epitopes). The ICD procedure is generally applied as a pretreatment step to remove endogenous IgG hindering detectability of antigens. After ICD, TES can be indeed detected with reasonably good sensitivity, which is, however, about twice lower than in blank serum and almost five times lower than in PBS (Figure 8). Notably, TES was not found in non-spiked anti-TES-IgG positive serum despite high seropositivity. In fact, high seropositivity does not necessarily correlate with the level of TES and may even occur a long time after past infection when 
TES antigens already left the circulation. ${ }^{32,39}$ Nevertheless, the results show that ICD is compatible with our detection method and does not lead to any increase in the background or false negative as the case for highly positive serum before ICD.

Taking into account the decrease in sensitivity, the sample dilution $(4 \times)$ in the ICD procedure, and possible additional sample dilution due to limited sample volume, a margin of sensitivity by a factor of 100 is expected to ensure the detection of TES in real samples, which corresponds to our previous study on detection of TES using HRP-labeled Nbs, leading to an LOD in serum after IDC of $0.9 \mathrm{ng} / \mathrm{mL} .{ }^{15}$ In the present work, the sensitivity has been improved by a factor of 10 , allowing detection at $20-100 \mathrm{pg} / \mathrm{mL}$ depending on the dilution factor.

Importantly, although the photoamperometric method does not quantify TES concentrations above $1 \mathrm{ng} / \mathrm{mL}$ in PBS, it detects TES down to a few $\mathrm{pg} / \mathrm{mL}$ - a concentration level that is inaccessible using previously reported ELISAs with conventional polyclonal and monoclonal antibodies (Table 1). These low levels are considerably more relevant for the diagnostic of the disease due to low amounts of TES present in the serum of patients with active infections. In general, the detection of biomarkers and pathogens at trace levels is of high interest in point-of-care and point-of-need diagnostics. Detection at comparatively high levels is a routine with ELISA and conventional lateral flow assays. Novel sensors address the need to detect antigens in the low concentration range without the use of high-end laboratory equipment.

Taking into account the lack of adequate laboratory diagnostic methods and specific clinical picture for covert toxocariasis, the developed setup can be offered for routine laboratory detection of TES. The sample throughput can be improved by the use of an electrochemical multiplexer and precisely positioned LEDs to provide sufficient and reproducible light flux to a set of sensors operating in parallel. Further development of a point-of-care device, however, is limited by the need for ICD. This issue can be addressed by selecting Nbs that recognize epitopes unavailable for endogenous IgG. Such cryptic epitopes, in theory, can be reached by $\mathrm{Nbs}$ due to their unique paratope architecture with a preferential recognition of concave epitopes. ${ }^{45}$ Moreover, production of the disposable photoamperometric sensors requires only low-cost chemo- and thermostable photosensitizers and low-cost procedures such as drop-casting and screen printing, leading to little additional costs.

In a broader context, the reported strategy could be adjusted for detection of other parasitic excretory-secretory antigens and other challenging biomarkers or pathogens, including viral antigens (as a better alternative to serological analysis). The importance of the development of highly sensitive methods for the detection of an infectious agent can be exemplified with the rapid tests to identify the SARS-CoV-2 antigens in nasopharyngeal swabs. In contrast to serological tests or RTPCR, the direct detection of antigens allows the identification of patients exactly during the period where they actively transmit the disease. ${ }^{46}$ However, sensitivity remains an important issue to address. We think that the enhancement established by the photocatalytic-electrochemical redox cycling strategy might extend the applicability of immunoassays and point-of-care devices for detection of antigenic biomarkers present at trace levels.

\section{ASSOCIATED CONTENT}

\section{Supporting Information}

The Supporting Information is available free of charge at https://pubs.acs.org/doi/10.1021/acs.analchem.1c02876.

Light-chopped linear sweep voltammogram of pNP after the subtraction of a blank measurement (PDF)

\section{AUTHOR INFORMATION}

\section{Corresponding Author}

Karolien De Wael - A-Sense Lab, University of Antwerp, 2020 Antwerp, Belgium; (1) orcid.org/0000-0003-44950748; Email: karolien.dewael@uantwerpen.be

\section{Authors}

Stanislav Trashin - A-Sense Lab, University of Antwerp, 2020 Antwerp, Belgium; 이이.org/0000-0002-4089-4251

Francisco Morales-Yánez - Department of Biomedical Sciences, Institute of Tropical Medicine, 2000 Antwerp, Belgium; Laboratory of Cellular and Molecular Immunology, Vrije Universiteit Brussel, 1050 Brussels, Belgium

Saranya Thiruvottriyur Shanmugam - A-Sense Lab, University of Antwerp, 2020 Antwerp, Belgium

Linda Paredis - Department of Biomedical Sciences, Institute of Tropical Medicine, 2000 Antwerp, Belgium

Erik N. Carrión - Department of Chemistry and Biochemistry and the Center for Functional Materials, Seton Hall University, South Orange, New Jersey 07079, United States

Idalia Sariego - Department of Parasitology, Institute of Tropical Medicine Pedro Kouri, 17100 Havana, Cuba

Serge Muyldermans - Laboratory of Cellular and Molecular Immunology, Vrije Universiteit Brussel, 1050 Brussels, Belgium; (i) orcid.org/0000-0002-3678-3575

Katja Polman - Department of Biomedical Sciences, Institute of Tropical Medicine, 2000 Antwerp, Belgium

Sergiu M. Gorun - Department of Chemistry and Biochemistry and the Center for Functional Materials, Seton Hall University, South Orange, New Jersey 07079, United

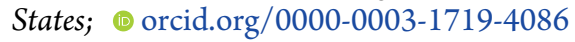

Complete contact information is available at: https://pubs.acs.org/10.1021/acs.analchem.1c02876

\section{Author Contributions}

All authors have approved the final version of the manuscript. Notes

The authors declare no competing financial interest.

\section{ACKNOWLEDGMENTS}

The Antwerp University Research Fund (BOF-DOCPRO), the Research Foundation - Flanders (FWO), and the Center for Functional Materials (USA) are thanked for the support of this work.

\section{REFERENCES}

(1) Tighe, P. J.; Ryder, R. R.; Todd, I.; Fairclough, L. C. Proteomics: Clin. Appl. 2015, 9, 406-422.

(2) Cohen, L.; Walt, D. R. Chem. Rev. 2019, 119, 293-321.

(3) Vanli, G.; Cuesta-Marban, A.; Widmann, C. PLoS One 2017, 12, No. e0188311.

(4) Weller, M. G. Anal. Chem. Insights 2016, 11, 21-27.

(5) Muyldermans, S. Annu. Rev. Biochem. 2013, 82, 775-797.

(6) Leow, C. H.; Fischer, K.; Leow, C. Y.; Cheng, Q.; Chuah, C.; McCarthy, J. Diagnostics 2017, 7, 52. 
(7) Li, H.; Sun, Y.; Elseviers, J.; Muyldermans, S.; Liu, S.; Wan, Y. Analyst 2014, 139, 3718-3721.

(8) Wang, H.; Li, G.; Zhang, Y.; Zhu, M.; Ma, H.; Du, B.; Wei, Q.; Wan, Y. Anal. Chem. 2015, 87, 11209-11214.

(9) Mi, L.; Wang, P.; Yan, J.; Qian, J.; Lu, J.; Yu, J.; Wang, Y.; Liu, H.; Zhu, M.; Wan, Y.; Liu, S. Anal. Chim. Acta 2016, 902, 107-114. (10) Pan, D.; Li, G.; Hu, H.; Xue, H.; Zhang, M.; Zhu, M.; Gong, X.; Zhang, Y.; Wan, Y.; Shen, Y. Chem. - Eur. J. 2018, 24, 9869-9876.

(11) El-Moghazy, A. Y.; Huo, J.; Amaly, N.; Vasylieva, N.; Hammock, B. D.; Sun, G. ACS Appl. Mater. Interfaces 2020, 12, $6159-6168$.

(12) Oloketuyi, S.; Mazzega, E.; Zavašnik, J.; Pungjunun, K.; Kalcher, K.; de Marco, A.; Mehmeti, E. Biosens. Bioelectron. 2020, 154, 112052.

(13) Morales-Yanez, F. J.; Sariego, I.; Vincke, C.; HassanzadehGhassabeh, G.; Polman, K.; Muyldermans, S. Int. J. Parasitol. 2019, 49, 635-645.

(14) Morales-Yánez, F.; Trashin, S.; Hermy, M.; Sariego, I.; Polman, K.; Muyldermans, S.; De Wael, K. Anal. Chem. 2019, 91, 1158211588 .

(15) Morales-Yánez, F.; Trashin, S.; Sariego, I.; Roucher, C.; Paredis, L.; Chico, M.; De Wael, K.; Muyldermans, S.; Cooper, P.; Polman, K. Parasites Vectors 2020, 13, 245.

(16) Magnaval, J.-F.; Fabre, R.; Maurières, P.; Charlet, J.-P.; de Larrard, B. Parasitol. Res. 1991, 77, 697-702.

(17) Magnaval, J. F.; Glickman, L. T.; Dorchies, P.; Morassin, B. J. Virol. Methods 2001, 39, 1-11.

(18) Goggins, S.; Naz, C.; Marsh, B. J.; Frost, C. G. Chem. Commun. 2015, 51, 561-564.

(19) Preechaworapun, A.; Dai, Z.; Xiang, Y.; Chailapakul, O.; Wang, J. Talanta 2008, 76, 424-431.

(20) Kreuzer, M. P.; O'Sullivan, C. K.; Guilbault, G. G. Anal. Chim. Acta 1999, 393, 95-102.

(21) Scheller, F. W.; Bauer, C. G.; Makower, A.; Wollenberger, U.; Warsinke, A.; Bier, F. F. Anal. Lett. 2001, 34, 1233-1245.

(22) Lisdat, F.; Ho, W. O.; Wollenberger, U.; Scheller, F. W.; Richter, T.; Bilitewski, U. Electroanalysis 1998, 10, 803-807.

(23) Cosnier, S.; Gondran, C.; Watelet, J.-C.; De Giovani, W.; Furriel, R. P. M.; Leone, F. A. Anal. Chem. 1998, 70, 3952-3956.

(24) Ciana, L. D.; Bernacca, G.; Bordin, F.; Fenu, S.; Garetto, F. J. Electroanal. Chem. 1995, 382, 129-135.

(25) Ho, W. O.; Athey, D.; McNeil, C. J. Biosens. Bioelectron. 1995, $10,683-691$.

(26) Thompson, R. Q.; Porter, M.; Stuver, C.; Halsall, H. B.; Heineman, W. R.; Buckley, E.; Smyth, M. R. Anal. Chim. Acta 1993, 271, 223-229.

(27) Ito, S.; Yamazaki, S.-i.; Kano, K.; Ikeda, T. Anal. Chim. Acta 2000, 424, 57-63.

(28) Trashin, S.; Rahemi, V.; Ramji, K.; Neven, L.; Gorun, S. M.; De Wael, K. Nat. Commun. 2017, 8, 16108.

(29) De Savigny, D. H. J. Parasitol. 1975, 61, 781-782.

(30) Conrath, K. E.; Lauwereys, M.; Wyns, L.; Muyldermans, S. J. Biol. Chem. 2001, 276, 7346-7350.

(31) Sariego, I.; Kanobana, K.; Junco, R.; Vereecken, K.; Nuñez, F. A.; Polman, K.; Bonet, M.; Rojas, L. Trop. Med. Int. Health 2012, 17, 711-714.

(32) Rodríguez-Caballero, A.; Martínez-Gordillo, M. N.; MedinaFlores, Y.; Medina-Escutia, M. E.; Meza-Lucas, A.; Correa, D.; Caballero-Salazar, S.; Ponce-Macotela, M. Parasites Vectors 2015, 8, 264.

(33) Gerdes, R.; Lapok, L.; Tsaryova, O.; Wöhrle, D.; Gorun, S. M. Dalton Trans. 2009, 1098-1100.

(34) Arvinte, A.; Mahosenaho, M.; Pinteala, M.; Sesay, A.-M.; Virtanen, V. Microchim. Acta 2011, 174, 337-343.

(35) Neven, L.; Shanmugam, S. T.; Rahemi, V.; Trashin, S.; Sleegers, N.; Carrión, E. N.; Gorun, S. M.; De Wael, K. Anal. Chem. 2019, 91, 9962-9969.

(36) Wei, Y.; Wu, K.; Wu, Y.; Hu, S. Electrochem. Commun. 2003, 5, 819-824.
(37) Wilkinson, F.; Helman, W. P.; Ross, A. B. J. Phys. Chem. Ref. Data 1995, 24, 663-677.

(38) Latch, D. E.; McNeill, K. Science 2006, 311, 1743-1747.

(39) Ishiyamna, S.; Ono, K.; Rai, S. K.; Uga, S. Nepal Med. Coll. J. 2009, 11, 9-13.

(40) Bautista-García, S. G.; Martínez-Gordillo, M. N.; PeraltaAbarca, G. E.; González-Bobadilla, N. Y.; Clavijo-Sánchez, K.; Chávez-Zea, A. L.; Hernández-Saavedra, A. E.; Huerta-López, J. G.; Pedroza-Meléndez, Á.; González-Garay, A. G.; Ponce-Macotela, M. Immun. Inflamm. Dis. 2021, 9, 435-442.

(41) Yokoi, K.; Kobayashi, F.; Sakai, J.; Usui, M.; Tsuji, M. Southeast Asian J. Trop. Med. Public Health 2002, 33, 33-37.

(42) Luo, Z.-j.; Wang, G.-x.; Yang, C.-l.; Luo, C.-h.; Cheng, S.-w.; Liao, L. J. Parasitol. 1999, 85, 252-256.

(43) Robertson, B. D.; Burkot, T. R.; Gillespie, S. H.; Kennedy, M. W.; Wambai, Z.; Maizels, R. M. Clin. Exp. Immunol. 1988, 74, 236241.

(44) Gillespie, S. H.; Bidwell, D.; Voller, A.; Robertson, B. D.; Maizels, R. M. J. Clin. Pathol. 1993, 46, 551-554.

(45) De Genst, E.; Silence, K.; Decanniere, K.; Conrath, K.; Loris, R.; Kinne, J.; Muyldermans, S.; Wyns, L. Proc. Natl. Acad. Sci. U. S. A. 2006, 103, 4586-4591.

(46) Berger, A.; Nsoga, M. T. N.; Perez-Rodriguez, F. J.; Aad, Y. A.; Sattonnet-Roche, P.; Gayet-Ageron, A.; Jaksic, C.; Torriani, G.; Boehm, E.; Kronig, I.; Sacks, J. A.; de Vos, M.; Bausch, F. J.; Chappuis, F.; Renzoni, A.; Kaiser, L.; Schibler, M.; Eckerle, I. PLoS One 2021, 16, No. e0248921. 